\title{
Managing Ethical Risks and Crises: Beyond Legal Compliance
}

\author{
Diane Huberman Arnold ${ }^{1}$, Keith Arnold ${ }^{2}$, Vanessa J. Arnold ${ }^{3}$ \\ ${ }^{1}$ Department of Philosophy, Carleton University, Canada; \\ ${ }^{2}$ Department of Philosophy, University of Ottawa, Canada; \\ ${ }^{3}$ Emily Carr University of Art and Design, Canada. \\ Email: diane_hubermanarnold@carleton.ca
}

Received September $9^{\text {th }}, 2010$; revised October $15^{\text {th }}, 2010$; accepted November $8^{\text {th }}, 2010$.

\begin{abstract}
Recent interest in culture stems from its power to explain corporate and organizational failures. Such failures are both internal and external: accounting fraud, management misconduct, harassment and bullying in the workplace, racism, sexism, environmental issues, and health and safety concerns. Current theory holds that these failures are to be explained partly by the particular, poor organizational culture and unhealthy climate, poor leadership, and by the misdeeds of a few bad apples. When economic conditions are negative, organizations look to legislation, regulations, and codes, to reform their culture, and manage the risks of organizational failure. Both the compliance strategy, demanding obedience to laws, regulations and codes, and the integrity or values strategy, focusing on ethics training, education, tone at the top, and the hiring of employees with integrity and values, are the mainstay of recent legislation and regulations in North America and the European Union. We criticize the reliance on legislation, regulations and codes, the focus of a compliance solution which we find inadequate, ineffective, and unenforceable. We suggest reliance on a front-end, proactive and preventive program of best, precautionary practices, will better meet the challenge, in prosperity or poverty, of setting corporate culture on the right track.
\end{abstract}

Keywords: Organizational Behavior, Business Law, policy, ethics

\section{Corporate Scandals}

We live in an age when every corporate or organizational misdeed, mischief or malfeasance is attributed to the culture of the organization or corporation. Here is a sampling:

"Even the most upright people are apt to become dishonest, and unmindful of civic responsibilities when placed in a typical corporate environment." (Wall Street Journal)

"A corporate culture blighted by infectious greed, is the cause of the breakdown in confidence among investors." (New York Times)

"If this scandalous laxity had not existed, the hubris of Enron's managers would not have mattered. A culture of corruption cannot develop if tough watchdogs are in place." (Washington Post)

These claims that certain business cultures may produce or foster bad behaviour and/or criminality, and overpower employees' personal values, have served as the favored explanation for many years, for the large corporate scandals that have occurred. This explanation, that culture produces the problems, is the foundation for recent developments in business law. (Trevino, 2007; Ferrell et al., 2008) Recent legislation seeks to punish bad corporate culture, seeks to restrict the harm which organizations might cause, and aims to promote ethical behaviour.

These complex matters can be highlighted by literature. Émile Zola offers a past but relevant way into these issues. $L a$ Curée is Zola's novel in the Rougon-Macquart series, about greed, violence and corruption in business. The event which takes place when the hounds are given the remains of the stag, after the hunt. The title and setting are, unfortunately, accurate and appropriate metaphors for our subject matter. The novel concerns Baron Haussmann's attempt to transform Paris from a medieval city into a modern one, following the example of London, in the 1860 's. In this redevelopment of Paris, there were fortunes to be made, scruples to be overcome, and morals to be discarded. Dummy credit lines were set up by unsavory financiers. The price of land and housing was artificially inflated. As a result, millionaires were made, while thousands were defrauded. (Zola 1874/1999)

Zola's novel follows the grim profiteering and social success of the corrupt Saccard family, as it makes its money in collusion with corrupt government officials, by trampling over victims and their rights. In the Preface to this saga of bribery, corruption, and financial malfeasance, Zola asks and answers two questions about the wrongdoing he describes:

Is the corruption caused by a society or culture that has gone bad, and is rotten to the core?

Is the solution to this problem to reform society and business, by new regulations and legislation?

Zola's answer suggests that the corruption in business requires more than a bad culture, to explain what happened. In his claim to be writing a natural history, Zola stands firm in his view that both bad apples and bad barrels, the evil people and the corrupt culture, are necessary to explain what was rotten in the with new legislation, will be required to reform it.

\section{Corporate Culture}

Zola did not distinguish the various kinds of scandal there are, but, in essence, everything we have seen of recent business scandals is in La Curée. There are internal problems - the fail- 
ure of a rigid hierarchical organizational structure, fraud, bribery, discrimination, corruption, cooking the books, kickbacks, and extortion. There are external failures - harassment, violence, bullying, nepotism and cronyism, and health and safety violations. Common risk factors appear -poor leadership, pressure to compromise standards, greed, cutting corners, setting unrealistic goals and overreaching expectations. (Crane \& Matten, 2010)

The evidence for the negative impact of a bad culture is overwhelming. Culture shapes workplace values, norms, policies and procedures. (McShane, 2001) Workplace behavior varies greatly from personal behavior, from the toxic boss who is still a wonderful spouse and parent, to the model employee at work who is a monster at home. These multiple-selves phenomena are inexplicable, unless we accept that organizational culture exists and greatly impacts workplace actions. (Card, 2005) Firms in the same industry, whose corporate culture differs greatly, will see up to a thirty percent difference in performance. Firms with similar cultures, which use different management strategies, will only see a five percent difference in performance. Clearly, organizational culture has the larger impact. (Shaw \& Barry, 2007) It is the operating culture, what an organization influence.

Zola wrote of the spreading of harm, of people who infect others. He explained the impact of a bad culture with a parallel to bad fruit, bruised, overheated and bacterially infected, which extends the damage to the rest of the barrel's contents. The bad apples are those who will do harm to the organization, intend to do harm, and whose own interests are their first, or only, priority. These are the toxic individuals whom Zola describes as plague-carriers, who infect others. (Zola, 1877/2009) The majority is the mass of swayable employees, who can be turned, and can tip the balance and change the culture for good or for bad. The counter-belief is that with strong legislation, there is a limit to the harm and influence of bad apples, rogue employees, and toxic bosses within an organization. It is believed that carrots and sticks, mitigating and aggravating motivators, help foster a good organizational culture. (Trevino \& Nelson, 2007)

There are four different combinations possible, between good and bad apples, and good and bad cultures. Only one of the four has the ideal of good apples interacting with good cultures. Legislation seeks to limit and influence the other three scenarios.

What goes wrong cannot be ignored. A bad culture will lose, for the organization, their good employees, who cannot or will not stand the pressure and discomfort of the unhealthy or toxic workplace, leaving only the bad apples that will bring the place down. Those who kept the values of the organization expensive; losing good people costs even more money. Lack of loyalty and commitment to the organization causes problems, and low morale costs even more. (Ferrell et al., 2008; Crane \& Matten, 2010)

\section{Established Strategies for Reforming Organizations}

There are three obvious options an organization at risk or in crisis will have. The organization may perceive the risks and vulnerabilities in functioning, and wish to reduce risk and prevent harm. Alternatively, the organization may already have suffered harm, and must adopt crisis management to prevent further harm and rectify its mistakes. (Karakowsky et al., 2005) Worst case scenario, the organization has already failed; it may be broken, not able to function or fulfill its mandate, and must transform or reform its culture. In all three cases, with varying degrees of urgency, the organization must adopt strategies to strengthen and repair its operating culture.

In the literature, there are three recognized strategies for repairing a culture. This task has been called 'managing ethics', though we prefer the later term 'resilience management', for sustainable organizations. The first two strategies for this purpose were described by Paine, who named them the compliance program, and the values or integrity program. The third strategy, which is a mixture of these two programs, which was depicted by Trevino as a more effective program, remains unnamed. (Paine, 1994; Trevino \& Nelson, 2007) around the world, relies on obedience to legislation, regulations, and enforcement of codes of ethics, and codes of conduct. These are often part of a formal, legislated, ethics program or package for an organization. The basis of this strategy is compliance with the relevant legislation; the best known of which are in the U.S. Compliance is legally mandated by the Federal Sentencing Guidelines [1991], Sarbanes-Oxley [2002] and the Amendments to the FS Guidelines [2004]. The U.K. and continental Europe have similar systems in place. In Canada, there are eighteen standards still to be introduced by the Ontario Securities Commission (OSC) which will do the same. By complying with these, management can hope to detect mischief and bad behaviour, punish violators, and divest them from the organization.

The values or integrity program attempts to instill values into the organization. It relies on careful testing and selection of new employees, hired with values aligned to the espoused culture. It endorses employee training and education in ethics, rewards programs, an ethics officer, and ethics champions. This integrity strategy is based on the belief that values, commitment and integrity should permeate the workplace, and should figure in everyday decision-making, as well as in all policy making. There is an attempt to establish an alignment between the espoused culture the organization claims to have, and the reality of the operating culture of the organization, so there will be no deviation.

The third program is a combination of these two strategies. It adopts the force and strengths of the compliance program, while recognizing that these techniques of the values or integrity program increases its transformational effectiveness. This third mixed strategy has been adopted by the U.S. as part of the legal amendments to the Federal Sentencing Guidelines.

\section{Strategic Evaluation}

We look first at the compliance strategy, with the force of law behind it. Compliance is now part of all government mandated ethics packages or programs. Each organization covered must have a code or compliance standard, which is to be communicated, monitored and audited. There must be an ethics officer, and/or an ethics committee, ready to adjudicate the issues and specific cases, serving as the corporate legal conscience. There are also strict governance requirements for the Board of Directors. This is reinforced with a system of sanc- 
tions for breaches, and whistle-blowing protection in place. (Ferrell et al., 2008; Trevino \& Nelson, 2007)

For any multi-national in the U.S., and for any other business located outside but operating in the U.S., these organizations are legally obliged, and have every incentive, to comply. Legal punishment under the U.S. Federal Sentencing Guidelines for unethical or illegal activity is mitigated or aggravated by how duly diligent the organization is, in adhering to its ethical program. However, an ethics program is an expensive undertaking for organizations, particularly in monitoring legal compliance.

In cost saving measures, companies find ways to minimize or skirt compliance. They search for loopholes, and put in place the bare minimum they companies judge that the espoused culture and codes are adequate protection. The real risks are neither managed nor anticipated. For example, when multinational Nortel's stock was trading high, it paid lip service to compliance, and abandoned the core of its ethics program, even firing the ethics officer. Later, when Nortel was under legal investigation for accounting fraud, and the stock price fell to under a dollar, Nortel re-instituted an ethics program, with a new ethics officer. It was not clear whether this was to appease investigators, to show compliance, or merely designed to boost the company image. In any event, it did not save the company. (Ho, 2005)

Paine herself evinced similar skepticism concerning the efficacy of the compliance strategy alone. Evidence suggests that this compliance strategy is only a short-term strategy, good for crisis management, but not for long term cultural change. While it is less costly for organizations to implement a basic compliance strategy, by writing a code and ordering everyone in the corporation to obey it, the newer versions of compliance are more complicated, and thus more expensive undertakings. (Paine, 1994)

Basic compliance programs bow to the lowest common denominator; they are minimalist. They may function well at ridding an organization of bad apples, because they are designed to punish regulatory violations and ethical breaches of set standards. But programs lapse, or loopholes are found, unless more than basic compliance is activated. Evidence indicates that compliance has marginal effect on the corporate culture. (Paine, 1994; Weaver et al., 1999) In the vast in place, while bad behaviour continues -and at the same rate.

This proves that a legal compliance program cannot serve to protect an organization against bad behaviour, nor promote good behaviour in an organization. Some of the most legislated and highly regulated organizations exhibit continuing ethical lapses. Recently, we have the example of BP and the harm it has caused to the environment, and the Gulf Coast states in the U.S. (McKay \& Huberman Arnold, 2010) Para-military police forces around the world, are also organizations with questionable cultures, and repeated, and marked, ethical failures. (Huberman Arnold \& Arnold, 2010) Ethics is not part of their culture, though regulations and legislation are.

We turn to the second strategy, the integrity or values program. This strategy is important since most multi-nationals and large organizations, while legally mandated to employ the compliance strategy, need to do more than the minimal legally required. Studies make clear that if efficacy were the criterion of strategy choice, the integrity or values strategy would be chosen. Evaluation of the integrity or values strategy alleges that it works better, to ethicalize an organization, especially in the long term. (Weaver et al., 1999) It is claimed to be the more effective way to manage ethics, helping to prevent crises, and to inculcate ethics throughout the organization. (Paine, 1994)

The integrity strategy is used more, and works best, in small and medium-size organizations, where it is actually possible to hold shared values, a shared concern for ethics, and a shared culture. In larger organizations, without the values strategy falls short. When a crisis is at hand, waiting "six to fifteen years" for a culture shift to be accomplished, is not feasible. (Trevino \& Nelson, 2007)

Paine herself case-studied three businesses of various sizes, which she claimed had already successfully integrated the integrity strategy. They were Martin Marietta, a U.S. defense contractor with sixty thousand employees, Novacare, a U.S. health service provider, and Wetherill Associates, a U.S. automobile electrical parts supplier. The last was the smallest, with only 350 employees. (Paine, 1994) With a view to seeing how well the strategy works and how long its good effects last, we researched the progress of these cited companies in the last fifteen years.

Martin Marietta was involved in scandals in the 1970s and the 1980s. In 1995 it merged with Lockheed, to form Lockheed Martin, with 135,000 employees. Since that time, it has not ceased to be involved in scandals across North America and Asia, accused of fraud, bribery, corruption, war profiteering. It has paid many millions of dollars in fines to the U.S. government, among other stakeholders. A current Google search for scandals involving Lockheed Martin draws an astounding 103,000 item long list. It is therefore not a good example of integrity at work.

Novacare Inc., when Paine looked at it, was a medium-sized health care and rehabilitation company, run under the vision of its CEO, Foster, who was later criticized for making deals that benefited himself more than any other stakeholders, and for holding stock valued at over thirty million dollars. Novacare trouble. Its income dropped dramatically with the reduced government payments for seniors' rehab, from Medicare. HealthSouth was, of course, later involved in scandals of fraud, accounting and bribery scandals, focusing on its president Richard Scrushy. Select Medical Corp became the parent company of Novacare, when it acquired that part of HealthSouth, in the wake of the scandals. Novecare has doubled in size, become the largest provider of rehabilitation services in the U.S., and focuses on profits, growth, and the number one spot in the industry. While there is still the same discussion of cutting out the "mom and pop" rehab centers from the inception of Novacare through its implosion in the ' 90 s, to its present state, there is no talk about workplace values or integrity. It is not a good example of integrity at work, and it was not sustainable.

Research reveals that Wetherill has expanded triple-fold with a thousand employees, and globalized. It is still privately owned, and has bought and taken over other businesses. It has outsourced much of its electronic work to Thailand. These electronic factories in Thailand are under investigation for health and safety violations, and human rights abuses, but nothing yet has been connected back to Wetherill. Wetherill has been cited by labor organizations for costing jobs, closing American factories, and for outsourcing work offshore. This again is a questionable paradigm for the integrity or values strategy.

From Paine's own three cases, it is clear that reliance on the 
integrity strategy to manage ethics risks and crises, has many pitfalls. Ironically, a problem that the integrity or values strategy faces, is that there is nothing that wholly voluntary, and lacking any compliance mechanisms, will fail.

There are other concerns in relying exclusively on the integrity program. In large corporations, where most ethical malfeasance is found, values are not much discussed. CEOs of large organizations are skeptical, and power and distance means values and ethics are seen as too touchy-feely or metro-sexual for 'real' businessmen to be concerned with, or to be comfortable discussing. (Quinn, 1997; Vyakarnam, 1997)

\section{The Third Strategy}

These difficulties have been recognized, and have prodded attempts to fuse the two strategies together, for managing risks and crises. What is achieved is a third, mixed or combined strategy. Under the most recent U.S. Federal Sentencing Guidelines Amendments, the integrity strategy, added to compliance, is now also required by law, to bolster a corporate culture that encourages legal and ethical behaviour.

These Federal Sentencing Guidelines amendments of April 2004 list a number of requirements. Companies are to promote an organizational culture that encourages ethical conduct, in that (a) the ethics programs must be effective, in promoting a culture that encourages a commitment to compliance with the law; (b) they must draft compliance policies which deal with harassment, discrimination, etc; (c) they must motivate employees to comply, by providing incentives; (d) they have a duty to introduce ethics programs which prevent and detect violations of the law; and (e) small to medium businesses are now also compliance programs, as well as an active integrity strategy with ethics training, and whistle-blower protection, to aid in decision-making. (Trevino \& Nelson, 2007)

The aim of the amendments and the original legislation is the promotion of a legal and an ethical organizational culture, and the prevention of wrongdoing and criminality. Although it does make more sense to take a two-pronged approach and combine the two strategies to gain the advantages of both, the effectiveness of this dual application is still in question. Trevino and Nelson (2007) give two examples of companies successfully using the third combined strategy - Merck and American Express.

Research shows that neither company has a noteworthy legal or ethical record. While American Express has been implicated in, and disciplined for, several scandals, including financial services scandal, taking government bailout funds in the recent recession, stock manipulation, a large fine for gender and age discrimination, and a vendetta and smear campaign against an international banking rival, (Rocco, 1992; Associated Press, 200 a) its lapses pale when compared to Merck.

Merck is one of the largest pharmaceutical companies in the world, and in recent years has been charged with massive ethical misconduct, including medical fraud, accounting scandals, ghostwriting of pharma journals and phony drug study reports, cover-ups of health and safety with Fosomax, Vytorin, and customers. (Associated Press, 2004b; Corporate Narc, 2010)

\section{Failure to Promote and Prevent}

The combined strategy promises more effectiveness than it can deliver. Legislation can never protect in advance, as it looks to the past, and serves best to punish after the fact. In reality, most wrongdoing is not prosecuted, and of the few cases that are taken up, fewer still end successfully. It is said that for every business crime prosecuted, there are ten reported, and forty unreported. (Soifer, 1997) Small businesses are rarely, if ever, charged. The hope of the mixed strategy is that it will deter or prevent unethical actions, but the risks of being caught are slight, and the rate of exposed malfeasance has remained constant over the years. If, however, the aim of the legislation is for organizations to want to behave ethically, to live up to their social and ethical responsibilities, then, the "law is the last resort". (Soifer, 1997)

U.S. Government fines have increased over the past twenty years for criminal unethical business conduct, from an average of $\$ 200,000$ to an average of $\$ 2$ million. Taking into account the fluctuation of businesses coming into and going out of existence, and the normal growth of the number of businesses over time, and factoring in economic ups and downs, the surprising truth is that the rates of criminal and unethical behaviour in business have remained constant. There are no sharp increases or declines, just a steady state. About $10-12 \%$ year. (Ferrell et al., 2008)

This implies that the three major strategies used to reform organizational culture, have had limited effect. Companies still tend to misbehave, especially in the downturns of economic cycles. Mathematically, this strongly signals that there is a normal distribution, a classic bell curve of ethical and unethical behaviour, where the ethical tail and the unethical tail remain constant and fixed, at about ten to fifteen percent each, and the majority of corporate and business behaviour falls in the middle. If more is at stake, if bottom line, or jobs, or contracts are on the line, ethics takes second place, or lower. The curve is skewed. Enron and Nortel are poster corporations for this.

Applying the Pareto Principle to this situation, it follows that eighty to eighty-five percent of unethical business behaviour is committed by fifteen to twenty percent of corporations, and these are mostly large organizations, with more than 2,500 employees. Not surprisingly, the majority of employees of large organizations believe their bosses or leaders are not honest, do not have high personal integrity, and they would not feel comfortable reporting workplace misconduct to them. (Berman, 2000) The same results are obtained from "What the Bagel Man Saw"; large organizations are more unethical than small ones. (Levitt \& Dubner, 2005) Investigation of the established strategies shows no magic bullet that will transform a failing organization into an ethical one.

\section{Crisis Management}

In the search for new and effective strategies, a theoretical distinction must be made between front end strategies and back end strategies. This uses the image of a boat, to explain what is meant by front end strategies and back end strategies. The usual set of strategies, the back end strategies, are needed for a boat/organization that runs into trouble. Organizations need ways to back out of that trouble, trying to fix whatever has gone wrong, whether the crisis is internal or external. However, none of this will prevent harm coming to the boat. Nothing to avoid the risk or to improve the capacities or capabilities of the or- 
ganization for dealing with potential or imminent harm is offered.

Back end strategies like compliance, then, are reactive and have limited effect. They typically operate ex post facto. Like the law, they are designed to deal with the past, with what has already happened. Our laws show what decisions, activities and outcomes we disapprove of, and what is punishable. (Soifer, 1997) Legislation, regulations, and codes cannot reach the goals of prevention and protection to which the U.S. Federal Sentencing laws are directed.

There are other reasons why these back end strategies come up short. There are risks and harm, damage to stakeholders and people's lives, which are so harmful and so enormous that they can never be repaired or reformed; they are unfixable. Punishing Merck does not heal heart attacks or bring back the dead. Punishing Madoff does not repay his victims or redress the harm done.

Secondly, no part of compliance deals with the known risks or impediments to an ethical organizational culture -rogue employees, toxic standards, and no recognition of internal resistance or criticism. (Karakowsky et al., 2005; Ferrell et al., 2008; Crane \& Matten, 2010) Back end strategies cannot prevent any of these, nor protect and organization from their risks, even backed by the force of the law.

Back end strategies cannot make people ethical, nor can they make organizations ethical. The ethical programs which are at the center of the Federal Sentencing Guidelines, and Sarbanes-Oxley, etc. have these goals, but do not provide the methods to reach them. They cannot close gaps they do not recognize. Compliance strategies, as back end strategies, cannot succeed in ethicalizing an organization, or positively impacting an organizational culture. There is no example of an organization that has been able to turn itself around, to transform its culture, using back end strategies.

\section{Front End Strategies and Risk Management}

Front end strategies are designed to operate ex ante, as a risk management technique. They are designed to protect, proactively, organizations from future wrongdoing and potential harm, to prevent future criminality and abuse, and to promote good behaviour and an ethical culture. In order to do this, front end strategies must protect organizations from their particular risks or vulnerabilities, which vary by industry and organization. (Walker, 2007) Such strategies must promote ethical behaviour by identifying any gaps there are, and impediments that exist, which served in the past to prevent the organization from fulfilling its social and ethical responsibilities, and its mandate. (Marcinow, 1996) Applied Ethics, in June 2010, suggested that there were three things an organization should do, to handle crises and catastrophes. (1) Where there is a high risk of moral hazard - usually shown by past events - adopt a precautionary principle. (2) Engage in communications and exchanges of ideas between the organization and all its stakeholders. (3) Accept preventive measures from regulators. (Markkula, 2010)

Regulatory oversight only helps only if it stands in defense of the stakeholders, and not the vested interests of the organization. It is clear in the case of Merck that this did not happen. The Federal Drug Agency (FDA) exhibited no oversight, and asked the pharmaceutical companies to regulate themselves, by writing their own regulations. (Corporate Narc, 2010) Similar practice is observable with BP offshore oil drilling and the collusion of the Federal Mineral Management Service, which asked BP to investigate itself and write its own oversight study reports. (Efstathiou, 2010)

\section{Gap Analysis}

Front end strategies, like the precautionary principle, make use of gap analyses. A gap analysis is an assessment which identifies what it takes, to move from one position to another. One kind of gap analysis is a vulnerability or risk analysis. For example, it is the kind involved in environmental protection, where potential hazards and threats to the environment are identified and assessed. Gap analysis here delineates ways to reduce or eliminate the risks.

A second useful type of gap analysis is an impediment analysis. Here, an organization audits its actual social and ethical performance, sets goals and desirable standards, and then identifies any impediments which prevent or might prevent the organization from reaching its ethical potential. (Walker, 2007)

The list of impediments and vulnerabilities is open ended. It is useful, nevertheless, to identify some best precautionary practices in management, which serve to close the gap on identifiable risks, and eliminate impediments to better behaviour.

One important precautionary practice in risk management for larger organizations is thinking small, using small scale structuring. UPS, for example, has been reorganized to resemble a group of family firms, with a flatter structure, each with its own independence, and autonomy in decision-making. This illustrates the strategy of dividing up a large business into a series of small businesses, to get the advantages of both structures. There are, then, within each individual self-regulated unit, greater chances for organizing and monitoring their own behavior and decision-making, but all units work toward the same goals and with the same purpose. (Putnam \& Feldstein, 2003)

Another precautionary practice involves partnering with civil society, to share policies, standards, and regulations. Civil society consists of nongovernmental organizations, not-for-profit organizations, interest or advocacy groups, volunteer and activist groups, religious groups, and local community groups. In the U.S., there are nearly two million such groups, and in Canada, nearly two hundred thousand. These two countries top the list in numbers of environmental issues, to fair trade concerns, to human rights protection. (Crane \& Matten, 2010)

Such groups serve as proxy stakeholders, Markkula's second point. They speak for and protect those without power or impact; they give voice to the voiceless. Such groups partnering with corporations assist in drafting laws and regulations, which identify case specific and industry-wide vulnerabilities, and formulate solutions. Civil society groups have been called 'the new regulators', in that they exert public pressure through demonstrations, pickets, publications, and the media, and this pressure is very effective in transforming organizational culture. (Brugmann \& Prahalad, 2007)

A third best practice, most contentious in the corporate world, is that of transparency. It is precautionary, preventive, and is open to stakeholders and regulators, so ensures all three Markkula points. Transparency, and its connection to honesty and rationality, opens up decision-making within an organization, 
making people and the organization accountable. (Paine et al., 2005) A lack of transparency, the refusal to be transparent in an organization, blocks scrutiny of decisions and actions. Lack of transparency gives rise to distrust, and to the belief that there must be something wrong that needs to be covered up or denied, from hidden agendas to unacknowledged goals. Hiding behind claims of privacy and confidentiality undermines accountability, and any claims to honesty, equity, and due process. (Woods \& Goss, 2009; London Times, 2010)

Trust, honesty and equity are communitarian values. Mutual communitarian trust is the basis of organizational behaviour. Trust allows organizations to deal with each other, without constant recourse to violence or the law. Business benefits, as does the entire community. (Sen, 2007) Front end precautionary strategies promote good behaviour, as they build or rebuild, trust.

\section{References}

Associated Press editorial (2004a). American Express Faces Disciplinary Action.

Associated Press editorial (2004b). Report: Vioxx linked to thousands of deaths.

Berman, Dennis, ed. 2000. Small virtues: entrepreneurs are more ethical. Business Week's Frontier.

Brugmann, Jeb and C.K. Prahalad. (2007). Co-creating business's new social compact, Harvard Business Review.

Card, Claudia. (2005). The atrocity paradigm: A theory of evil. New York: Oxford,

Corporate Narc. (2010). Merck Accounting Scandal, accessed.

Crane, Andrew \& Dirk Matten. (2010). Business ethics: managing citizenship and sustainability in the age of globalization. Oxford: Oxford.

Efstathious Jr., Jim. (2010). Drilling regulators banned by U.S. from dealing with friends, relatives. Bloomberg News.

Ferrell, O.C., John Fraedrich \& Linda Ferrell. (2008). Business Ethics: Ethical Decision Making and Cases. $6^{\text {th }}$ ed., Boston: Houghton Mifflin.

Ho, Vanessa. (2005). Cautious Optimism Greets Nortel's Appointment of Ethics Chief. ITWorldCanada.com, Jan. 16,

Huberman Arnold, Diane \& Keith Arnold. (2010)Broken Organizations.

Karakowsky, Len, Archie B., Carroll \& Ann K. (2005). Buchholtz, Business and Society: Ethics and Stakeholder Management. Toronto: Nelson-Thomson.

Levitt, Steven D. \& Stephen J. (2005). Dubner. Freakonomics. New York: Harper Collins.
London Times. (2010). Editorial. Private Life. Public Good

Marcinow, Diane M. (1996). The paradox of ethical resistance: why do individuals frequently encounter retaliation for 'doing the right thing'? Proceedings of the Fifth Conflict Resolution Symposium. Ottawa: Carleton University. 64-81.

Markkula. (2010). Center For Applied Ethics, Managing Risk Ethically podcast.

McKay, Ruth \& Diane Huberman Arnold. (2010). Sustainable Enterprise: Crisis Management and Culture Transformation.

McShane, Steven L. (2001). Canadian Organizational Behaviour, $4^{\text {th }}$ ed. Toronto: McGraw-Hill Ryerson.

Paine, Lynn S. (1994). Managing for organizational integrity. Harvard Business Review. 17-106.

Paine, Lynn S., Rohit Deshpande, Joshua D. Margolis \& Kim Eric Bettcher. (2005). Up to code: Does your company's conduct meet world-Class standards? Harvard Business Review. pp. 122-135.

Putnam, Robert D. \& Lewis M. Feldstein. (2003). Better Together: Restoring the American Community. New York: Simon and Schuster.

Quinn, John. J. (1997). Personal ethics and business ethics: The ethical attitudes of owner/managers of small business. Journal of Business Ethics. 16(2). 119-127.

Rocco, Fiammetta. (1992). American express: Vendetta against banking rival. The Economist.

Sen, Amartya. (2007). Markets and the role of ethics in capitalism. Moral Issues in Business, $10^{\text {th }}$ edition. William H. Shaw and Vincent Barry, eds. Belmont, CA: Thomson Wadsworth.

Shaw, William H. \& Vincent Barry. (2007). Moral Issues in Business, $10^{\text {th }}$ ed. Belmont, CA: Thomson Wadsworth.

Soifer, Eldon. (1997). Ethical Issues: Perspectives for Canada, $2^{\text {nd }}$ ed. Peterborough, Ontario: Broadview.

Trevino, L. K. \& Katherine A. Nelson. (2007) Managing Business Ethics, $4^{\text {th }}$ ed. Hoboken, NJ: Wiley.

Vyakarnam, S., Bailey, A., Myers, A. \& D. Burnett. (1997). Towards an understanding of ethical behavior in small firms. Journal of Business Ethics. 16(15), 1625-36.

Walker, David. (2007). Counter-Terrorism Strategy. London: Charity Commission.

Weaver, Gary R., Linda Klebe Trevino \& Philip L. Cochran. (1999). Corporate ethics programs as control systems: Influences of executive commitment and environmental factors. Academy of Management Journal。 42(1). 41-57.

Woods, Richard \& Richard Goss. (2009). The bullying of common sense. Sunday Times.

Zola, Émile. La Curée. (1874) Paris: Gallimard Folio Classique, ed. Henri Mitterand, 1999.

Zola, Émile. L'Assommoir. (1877) translated by Robert Lethbridge and Margaret Mauldon. New York: Oxford World's Classics, 2009. 